\section{Runoff Forecasting and Its Application in Reservoir Operation and Flood Warnings in Nepal,}

Anup Khanal, Netra Prasad Timalsina and Prof. Knut Alfredsen

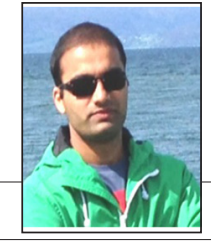

Anup Khanal

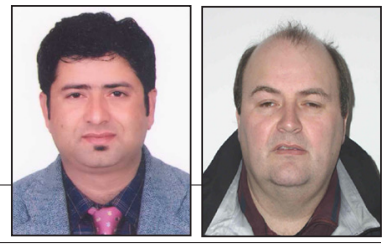

Netra P. Timilsina

Prof. Knut Alfredsen

Abstract: Runoff forecasting is a very useful tool in hydrology to predict runoff based on a weather forecast. In developed countries, the method is also currently used for flood forecasting, and to predict runoff for hydropower reservoirs and water allocation for irrigation. But this is not the case in Nepal. The purpose of this paper is to demonstrate how to set up a system for runoff forecasting for a Nepalese catchment and illustrate how these procedures could be utilized in reservoir operation and flood warnings. This paper provides the necessary steps for implementing such a system in Nepal, including the selection of a meteorological forecast model, bias correction of the model output, HBV model set up, and runoff forecast simulation.

Key words: Runoff forecasting, bias correction, HBV model calibration, warning limits, Nepal

\section{Introduction}

$\mathrm{N}^{2}$ epal is the second richest country in the world in water resources and its 6,000 rivers on a steep gradient have made the country an ideal place for hydropower development. Nepal could accrue significant economic benefits through an effective utilization of water resources. Effective runoff forecasting system could be a key tool for day to day operational strategies for the optimum use of water resources, including reservoir operation and flood forecasting.

Flood forecasting is of particular interest to Nepal as the country has faced an increasingly serious flood threat during the monsoon each year. In June 2013, for example, there was extensive loss of human life and property due to floods on the Mahakali River from intense rains. Northern Uttarakhand and the Darchula district in western Nepal suffered devastating destruction. In Darchula district the district headquarters were washed away and more than 100 families saw their homes washed into the raging flood torrents.

Runoff forecasting can be a very useful tool in water resource planning and flood mitigations. However, accurate forecasting of runoff can be challenging: The accuracy of the runoff forecast the quality of meteorological forecasts (precipitation and temperature) and the ability of the calibrated hydrological model to represent the actual response of the catchment.

This paper presents a framework to establish a flood warning system in Nepal and to use runoff forecasting for an effective operation of Kulekhani hydropower plant.

\section{Study Area}

The Kulekhani catchment is located at the northeast part of Makwanpur district which lies $21 \mathrm{~km}$ southwest of Kathmandu, Nepal. The catchment area is approximately $126 \mathrm{~km}^{2}$. The depends on surrounding area is composed rugged hill terrain surrounded by numerous mountains and valleys.

Kulekhani I (hereafter called as only 'Kulekhani') is the only reservoir hydropower plant in Nepal. Its total installed capacity is $60 \mathrm{MW}$ divided into two units each of $30 \mathrm{MW}$. The annual expected energy generation capacity as primary energy is 165 GWh and 46 GWh as secondary energy.

\section{Materials and Methodology Concept design}

A successful runoff forecasting system involves many steps to be carried out in sequence. However, the approach can vary according to the study site, selection of the hydrological model, and the meteorological forecast model. Figure 1 illustrates the steps that were carried out in preparing our work. The boxes in light green indicate the tasks to be completed for set up, and light blue boxes indicate tasks that require daily execution.

\section{Data acquisition}

Both measured and forecasted meteorological data (precipitation and temperature) are used in modelling. The measured data is employed for model setup and

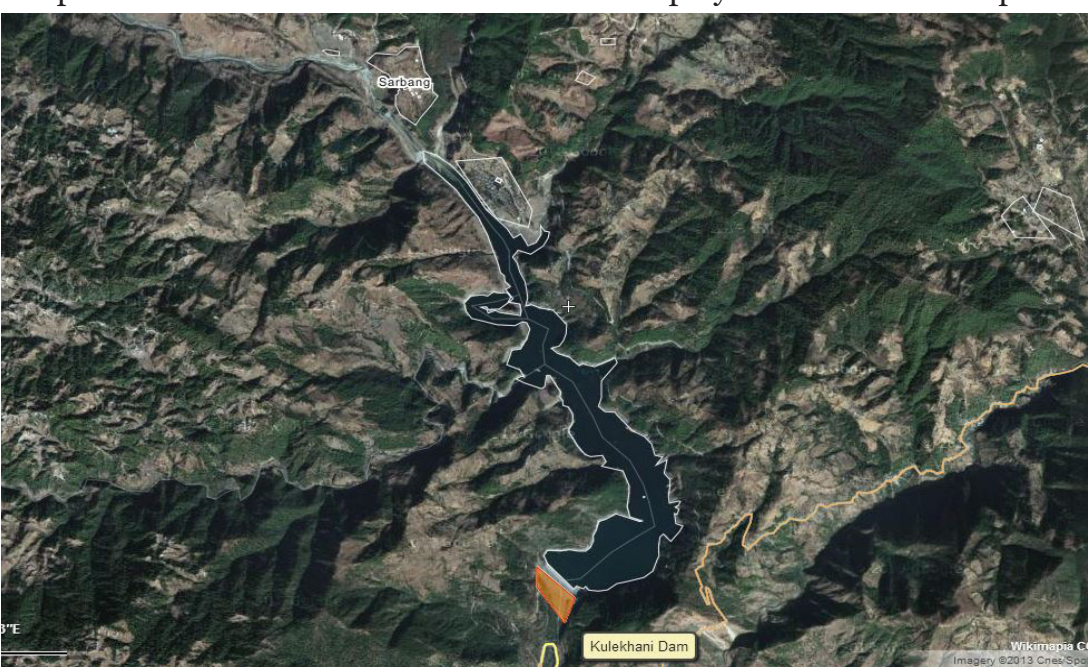

Figure 1: A satellite image of study area, Kulekhani catchment (Source: Google) 


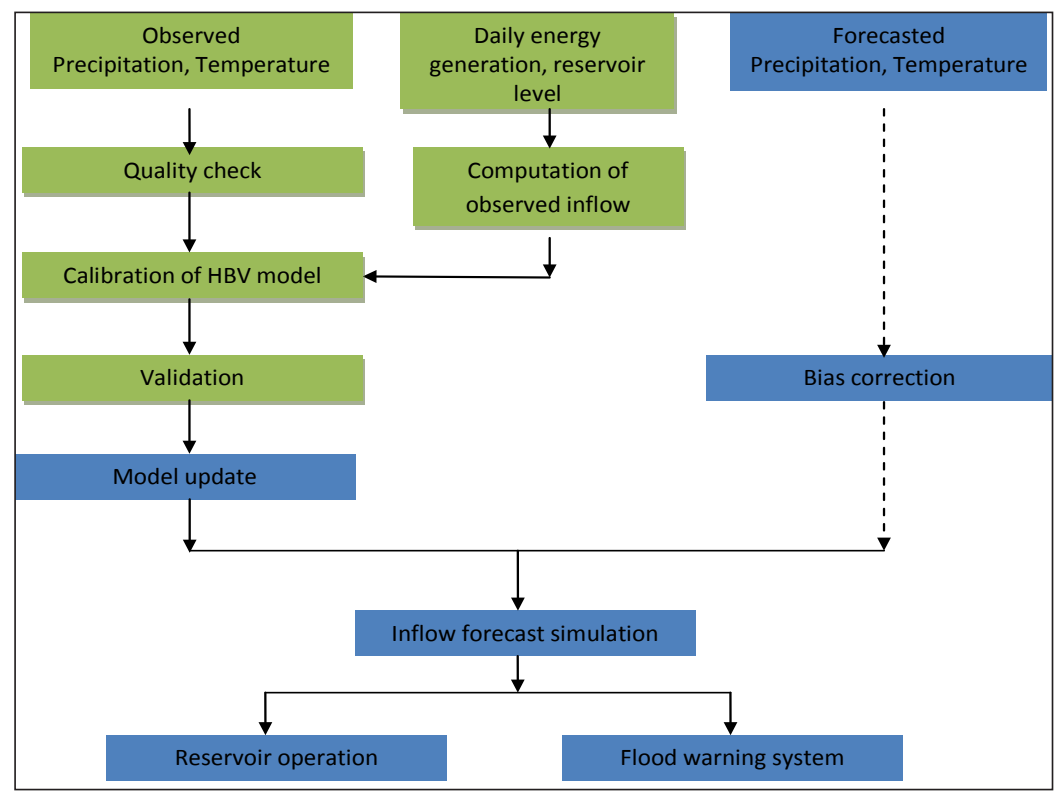

Figure 2: Steps involved in runoff forecasting and its application, a case study of Kulekhani catchment

forecasted data for operating inflow prognoses. We chose the period 2007-2011 for the HBV model calibration. However, data for only 2007-2009 were used in bias correction since earlier forecasted data were not available in the system.

All the measured precipitation and temperature data were collected from the Department of Hydrology and Meteorology (DHM) under the Ministry of Science, Technology and Environment, Nepal. All these data are passed through quality control such as visual inspection, accumulation plots, and double mass curve. Missing data are approximated and supplied using the inverse distance method (Khanal, 2013).

Meteorological forecasts data used in this study are outputs of the Global Forecast System (GFS) model which is run with $0.50 \times 0.50$ horizontal spatial resolution approximately equivalent to $50 \mathrm{~km} \mathrm{x} 50 \mathrm{~km}$ and temporal resolution of three hours. These data are obtained from the Research Data Archive (RDA) which is maintained by the Computational and Information Systems Laboratory (CISL) at the National Center for Atmospheric Research (NCAR). The original data are available from the RDA ${ }^{1}$ in dataset number ds335.0.

Meteorological forecast data are stored in GRIB (Gridded Binary or General Regularly-distributed Information in Binary) form, which can be read with various software packages. We used code developed in the $\mathrm{R}$, programming language (Team 2011) to read the GRIB files which contain meteorological forecasts. When both measured and forecasted meteorological data were ready, a comparison study were carried out and found large discrepancies between them, which made bias correction necessary.

\section{Bias correction to model outputs}

written regarding adjustment methods for daily output from weather models. Engen-Skaugen (2007) describes some bias correction methods for climate model data based on a method of preserving monthly variability. Some traditional techniques such as the delta change method is also used in different ways to solve problems with local representatives by concentrating on the changes rather than the absolute values, particularly in studies of climate change signals. The delta change method modifies the time series obtained by the RCM or the output from global forecast model by altering the variability; however, this method is not applicable to scenarios transient in time. The spline method smoothens out the mean monthly temperature values to daily values, neglecting the day-to-day variability. Two advanced method for bias correction such as the empirical bias correction method and the statistical bias correction method are the latest development in bias correction.

For the present case, we used the statistical bias correct method. Unlike the empirical adjustment method, which requires long observational data series, the statistical method can be applied when limited observational data are available (Engen-Skaugen 2007). The statistical bias correction method is used for correcting climate/weather model output to produce internally consistent fields that have the same statistical intensity distribution as the observations. This method is considered to be a robust statistical bias correction method, which was tested and validated by Piani et al. (2010) using regional model output over Europe from the ENSEMBLES project. This method also derives some form of transfer function using daily observed and simulated data from the control period and maintains the statistical distribution of the daily precipitation in analysis period.

The statistical bias correction method is based on the initial assumption that both the observed and simulated probability distribution can be well approximated by gamma distribution (Eq.1).

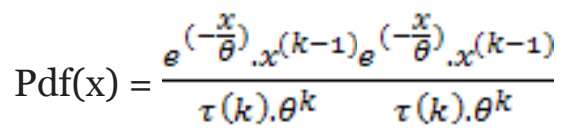

Where, $\mathrm{x}$ is daily precipitation. $\mathrm{K}$ and $\theta$ are the shape and scaling parameter, respectively. $\tau(k)$ is the gamma function evaluated at $\mathrm{k}$.

In our study, two years (2007 and 2008) were considered as the control period and the year 2009 was used as the analysis period to demonstrate the applicability of the model. The transfer function derived by using daily precipitation data from control period was applied to the daily precipitation forecasts in analysis period to correct biases. 
Two histograms were plotted, one using GFS model data and the other using observed daily precipitation within the control period. No subdivision of seasons was done at this point. The bin size was set to be $2 \mathrm{~mm} /$ day, while the lower limit of the lowest bin was set at $0.01 \mathrm{~mm} /$ day. This was done to remove dry days from the statistics. The histograms of both observed and simulated daily precipitation are fitted with the twoparameter $(k, \theta)$ gamma distribution defined in Eq. 1. In practice, the fitting was carried out by plotting the histograms with different sets of $\mathrm{k}$ and $\theta$ values and the best value of $k$ and $\theta$ were selected by visual inspection of the graph. The model output obtained its best fit with $\mathrm{k}=$ 0.71 and $\theta=17.5$, while as observed precipitation best fits a distribution with $\mathrm{k}=0.48$ and $\theta=23.0$.

Figures show that the daily precipitation forecast for the control period (2007 and 2008) is well fitted into gamma distribution and so is daily observed precipitation.

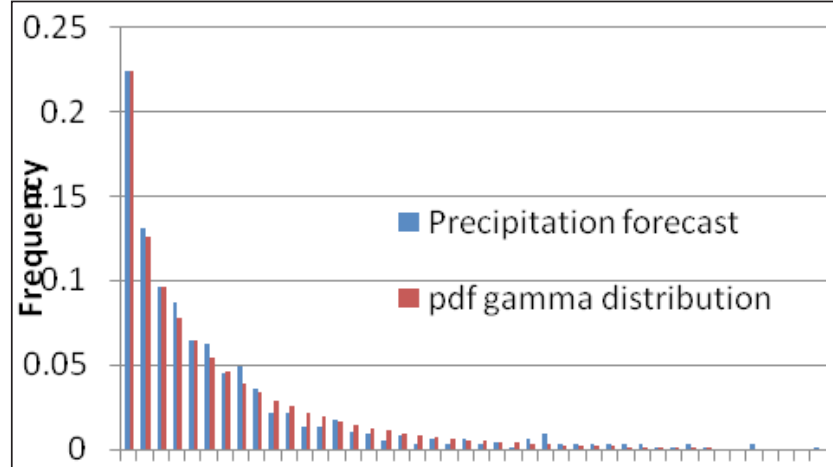

2814202632384450566268748086 Daily Precipitation

Figure 3: Fitted gamma distribution for precipitation forecast in control period

To derive the transfer function the cumulative distribution (cdf) was plotted with the simulated and observed daily precipitation value. The cdf was calculated as (Eq.2).

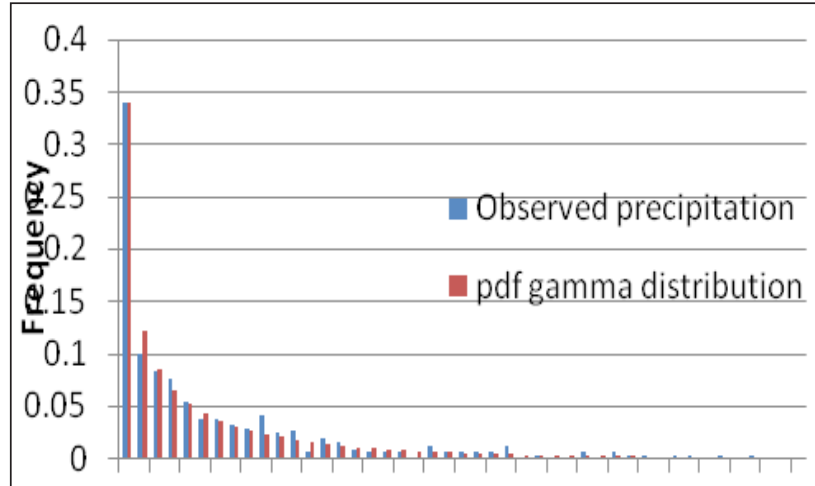

$\begin{array}{llllllllllll}2 & 10 & 18 & 26 & 34 & 42 & 50 & 58 & 66 & 74 & 82 & 90\end{array}$ Daily Precipitation, $\mathrm{mm}$

Figure 5: Fitted gamma distribution for observed precipitation in control period $\operatorname{cdf}(x)=\int_{0}^{x} \frac{e^{\left(-\frac{x}{\theta}\right)} \cdot x^{(k-1)}}{\tau(k), \theta^{k}} d x \quad \int_{0}^{x} \frac{e^{\left(-\frac{x}{\theta}\right)} \cdot x^{(k-1)}}{\tau(k), \theta^{k}} d+\operatorname{cdf}(0)$

Where, $x, k, \theta$ and ${ }^{\tau(k)}$ hold the same meaning as in Eq.1 and $\operatorname{cdf}(0)$ is the fraction of the days with no precipitation.

The desired transfer function $\mathrm{y}=\mathrm{f}(\mathrm{x})$ obeys the relationship: $c \mathrm{~cd}_{\text {obs }}(\mathrm{f}(\mathrm{x}))=\mathrm{cdf}_{\text {sim }}(\mathrm{x})$, where $\mathrm{x}$ and $\mathrm{y}$ are the simulated and corrected values of daily precipitation respectively and can be derived graphically from figure 6 . AutoCAD 2D was used to generate the transfer function. The transfer function $\mathrm{y}=\mathrm{f}(\mathrm{x})$ thus derived from AutoCAD is shown in figure 7.

The degree to which $f(x)$ deviates from the $y=x$ line as shown in figure 7 is a measure of the difference

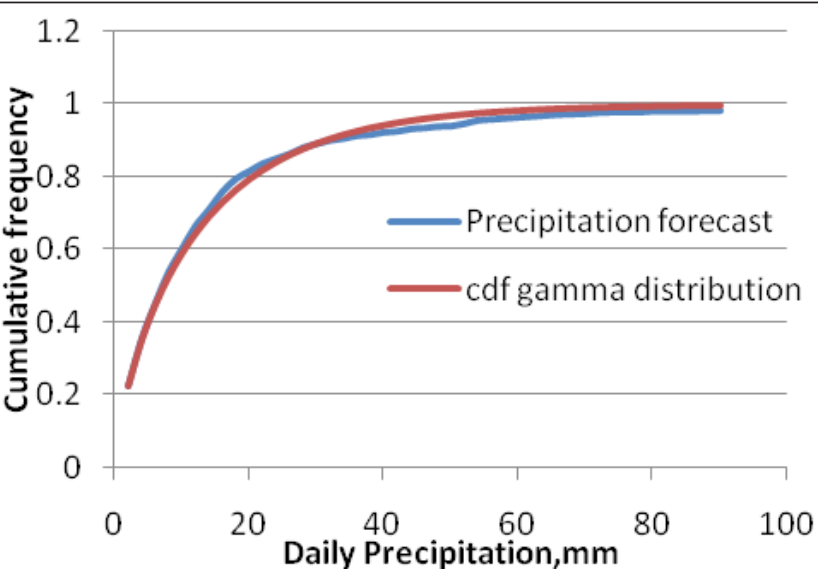

Figure 4: Fitted cumulative distribution for precipitation forecast in control period

between the observed and simulated pdfs. Thus the derived transfer function $(\mathrm{y}=-3 \mathrm{E}-05 \times 3+0.0028 \mathrm{x} 2+$ $0.6775 \mathrm{x}-4.0517$ ) was used to correct the simulated daily precipitation in analysis period.

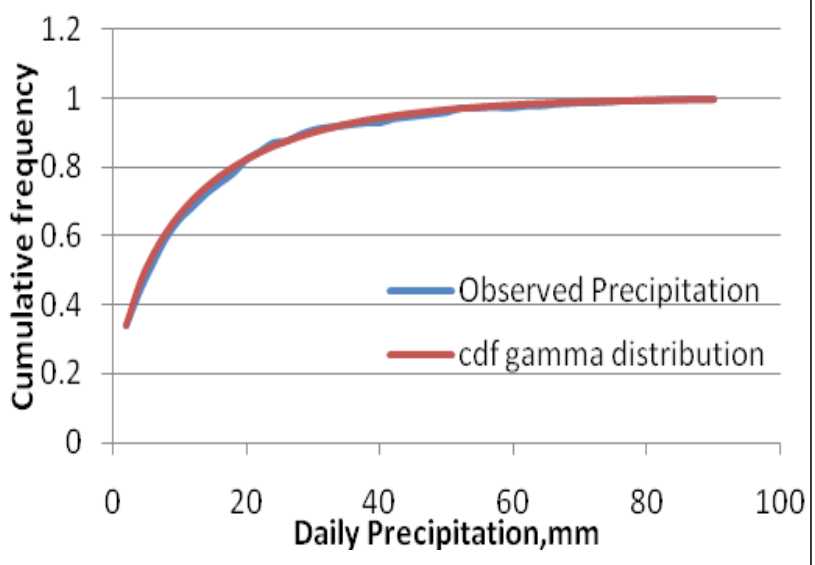

Figure 6: Fitted cumulative gamma distribution for observed precipitation in control period

Calibration of HBV model

Since recorded runoff from the Kulekhani catchment for 


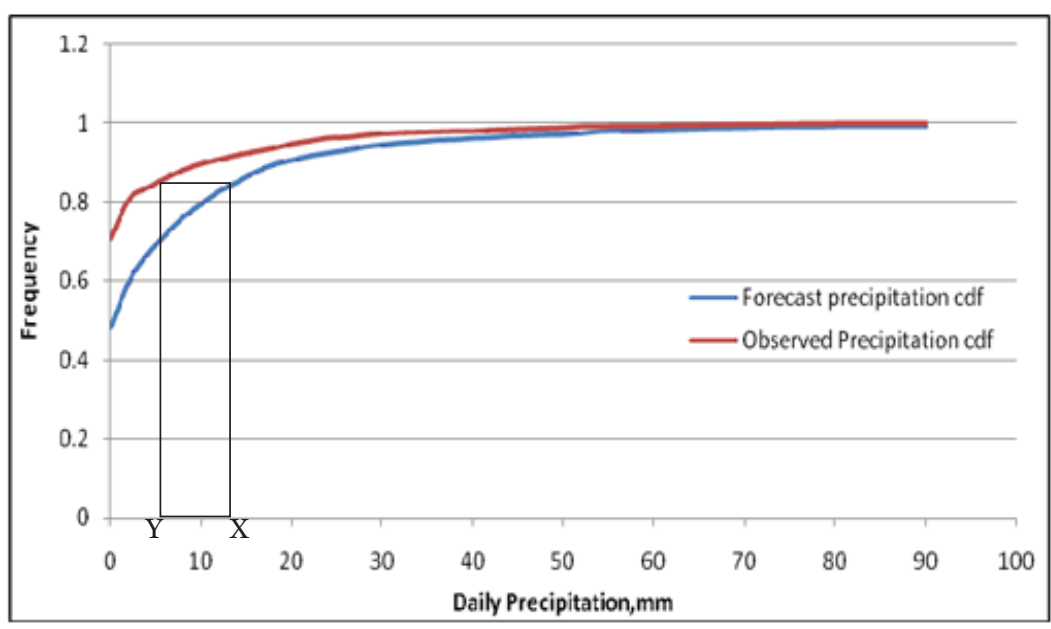

Figure 7: Cumulative gamma distribution including no precipitation days in control period

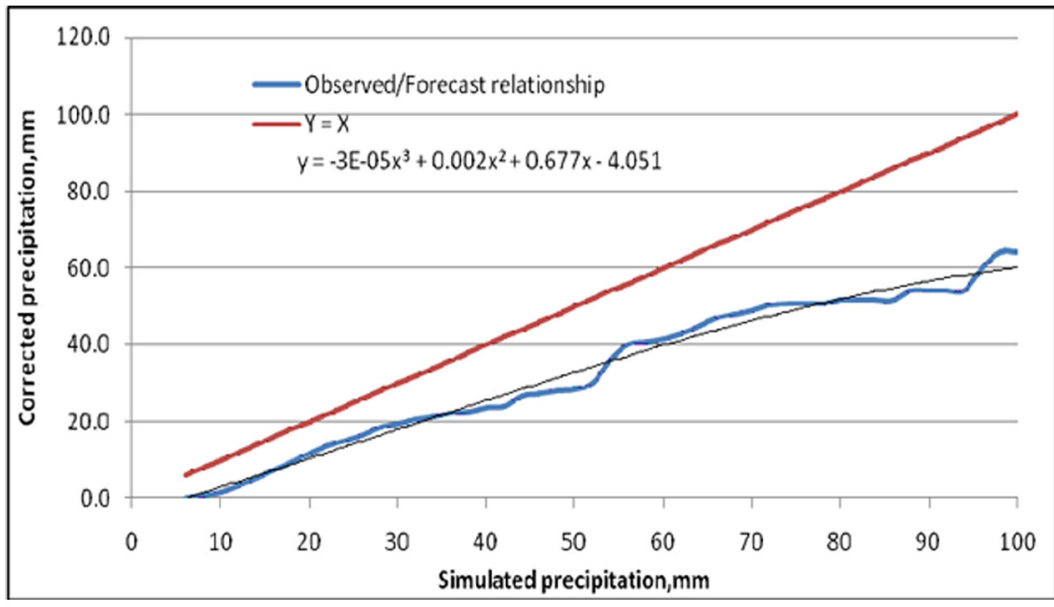

Figure 8: Transfer function which follows the equation $\mathrm{cdf}_{\mathrm{obs}}((\mathrm{fx}))=\mathrm{cdf}_{\mathrm{sim}}(\mathrm{x})$
PET (o) are adjusted depending on the number of days $\mathrm{N}$ in a month (1-31) and the duration of average monthly day light $\mathrm{d}$ (in hours), which is a function of season and latitude (Xu and Singh 2001).

$$
\operatorname{PET}=\operatorname{PET}(\mathrm{O}) \times\left(\frac{d}{12}\left(\frac{N}{30}\right)\right)
$$

In which PET is the adjusted monthly potential evapotranspiration ( $\mathrm{mm}), \mathrm{d}$ is the duration of average monthly daylight (hr); and $\mathrm{N}$ is the number of days in a given month, 1-31 (days).

\section{Runoff forecast simulation}

Model updating is the first crucial step in runoff forecast simulation process. Before the forecast is run, it is very important that correct 'starting' conditions in the model are established. Model updating is done with the model parameters determined through a model calibration process or preferably by changing model states or input values to get similarity between the simulated and observed value.

The updated HBV model is run at eight consecutive days based on bias corrected meteorological forecasts.

As an example, in our study, the first runoff forecast simulation was run at 01st August, 2009 on meteorological the study period of 2007-2009 were not available, daily runoff to the Kulekhani reservoir was computed by an indirect method based on the daily reservoir level and the energy generation from Kulekhani I Hydropower Plant.

The computed input potential evaporation required for driving the HVB, the Thornthwaite method, was used to compute the average monthly values of potential evapotranspiration (Ponce, 1989). The method is based on an annual temperature efficiency index $(\mathrm{J})$, defined as the sum of 12 monthly values of heat index (I) and average monthly values of daylight hours (d). I is the function of mean monthly temperature (T), in degrees Celsius as shown below:

$$
\mathrm{I}=\left(\frac{T}{5}\right)^{1.514}
$$

Unadjusted evapotranspiration is calculated by

$$
\operatorname{PET}(0)=1.6 \times\left(\frac{10 T}{J}\right)^{c}
$$

Where, $\operatorname{PET}(\mathrm{O})$ is potential evapotranspiration at $\mathrm{O}^{\circ}$ latitude in centimeters per month and $\mathrm{c}$ is an exponent evaluated as

$\mathrm{c}=67.5 \times 10^{-8} \mathrm{~J}^{3}-77.1 \times 10^{-6} \mathrm{~J}^{2}+0.01792 \mathrm{~J}+0.49239$

The unadjusted monthly evapotranspiration values forecasts for the coming seven days (August 2-August 6). Similarly, the model was again run at the second day (August 2) with the meteorological forecasts that are made from second day for coming seven days (August 3-August 7). Then the process was repeated for eight successive days with seven day forecasts for each day².

\section{Application of runoff forecast in reservoir operation}

Reservoir operation is one of the important applications of runoff forecasting as it calculates optimal production profile based on the probable future runoff and price variations. Knowing the short-term runoff and price level of energy, it is possible to decide whether reservoir water should be stored for future production or used in the present to get the optimum benefit from the project. The strategy of the reservoir operation is to reduce spill by preserving storage capacity to capture coming floods and to maintain the long term operational strategy of the reservoir within the short-term (i.e., to reserve water for the dry period).

Incorporating all the facts associated with energy planning in the Nepalese context, Shrestha (2012) developed a tailor-made model for Kulekhani reservoir operation. This model has the capacity to predict the 
probable extent of load-shedding and reservoir levels for seven days in advance.

\section{Results and discussion}

The HBV model calibrated for the Kulekhani catchment was carried out by manually adjusting parameter combinations to produce the best possible correspondence between observed and simulated runoff. Typical values (Killingtveit and Sælthun 1995) and the calibrated parameter set $\left(\mathrm{R}^{2}=0.76\right)$ are also presented in table 1. and water volume are shown in figure 9.

In figure 9, we see that the variability of flow over time is well maintained and the simulated water volume follows the observed water volume quite closely.

The low value of $\mathrm{R}^{2}=0.76$ can also be explained by the uncertainty in the computed runoff from reservoir data. Uncertainty in reservoir level recordings and turbine efficiency will directly influence the result.

It must also be noted that the value of $\mathrm{R}^{2}$ in this range is also due to the unavailability of long observational timeseries. In our study, there were 18 parameters that

\begin{tabular}{|c|c|c|c|c|c|}
\hline \multicolumn{2}{|c|}{ Meaning } & Value range & $\begin{array}{c}\text { Default } \\
\text { value }\end{array}$ & Units & $\begin{array}{c}\text { Calibrated } \\
\text { value }\end{array}$ \\
\hline Name & Thresholt temperature Rain/Snow & $-1.0-2.0$ & 1.0 & ${ }^{\circ} \mathrm{C}$ & -1.0 \\
\hline Ts & Thresholt temperature Snowmelts & $-1.0-2.0$ & 0.0 & ${ }^{\circ} \mathrm{C}$ & -1.0 \\
\hline CX & Degree-day-factor & $3.0-2.0$ & 4.0 & $\begin{array}{c}\mathrm{mm} /{ }^{\circ} \mathrm{C} \\
{ }^{*} \text { Day }\end{array}$ & 3.0 \\
\hline CFR & Re-freezing efficiency in snow & $0.0-0.01$ & 0.005 & & \\
\hline PKORR & Precipitation correction - Rainfall & $1.05-1.2$ & 1.05 & & 1.0 \\
\hline SKORR & Precipitation correction - snowfall & $1.15-1.5$ & 1.2 & & 1.15 \\
\hline TGRAD & Temperature lapse rate for clear days & $-0.6--1.0$ & -1.0 & ${ }^{\circ} \mathrm{C} / 100 \mathrm{~m}$ & -1.0 \\
\hline TVGRAD & Temperature lapse rate during precipitation & $-0.4--0.6$ & -0.4 & ${ }^{\circ} \mathrm{C} / 100 \mathrm{~m}$ & -0.5 \\
\hline PGRAD & Precipitatin lapse rate & $1.0-1.10$ & 1.05 & & 1.0 \\
\hline FC & Field capacity in soil moisture zone & $75-300$ & 150 & $\mathrm{~mm}$ & 300.0 \\
\hline LP & Thresholt value for potET in soil moisture & $70 \%-100 \%$ & 100 & $\%$ of FC & 250.0 \\
\hline$\beta$ & Parameter in soil moisture routine & $1.0-4.0$ & 2.0 & & 1.0 \\
\hline UZL & Threshold level for quick runoff in upper zone & $10-40$ & 20 & mm & 40.0 \\
\hline KUZ1 & Recession constant in upper zone & $0.1-0.5$ & 0.3 & $1 /$ day & 0.34 \\
\hline KUZ & Recession constant in upper zone & $0.05-0.15$ & 0.1 & $1 /$ day & 0.12 \\
\hline PERC & Percolation from upper to lower zone & $0.5-1.0$ & 0.6 & $\mathrm{~mm} /$ day & 3.62 \\
\hline KLZ & Recession constant in lower zone & $0.005-0.002$ & 0.001 & $1 /$ day & 0.006 \\
\hline
\end{tabular}

Table 1: Free parameters in the HBV model (Killingtveit and Sælthun, 1995) and calibrated value

In addition to an attempt to get highest $\mathrm{R}^{2}$ value, high attention was also given to reduce the error in water balance throughout the calibration period.

The snow parameters are insensitive since Kulekhani catchment does not have snow. The percolation from upper to lower zone (PERC) and precipitation correction rainfall (PKORR) for the Kulekhani catchment were found to be out of the recommended range, but acceptable.

The timeseries plot of observed and simulated runoff

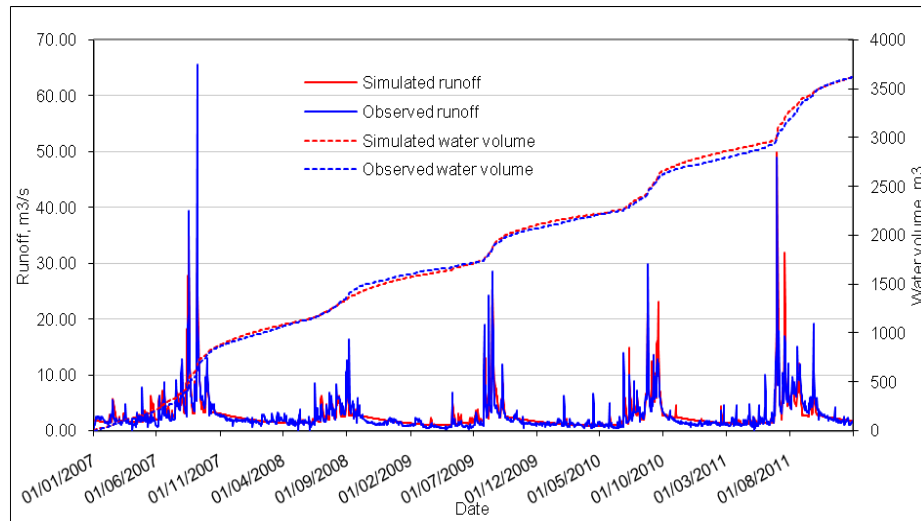

Figure 9: Observed and simulated runoff for Kulekhani catchment 2007-2011 required adjustment through calibration. The large number of parameters underscores the idea that long data series are needed to produce more reliable results. It is also worthwhile to mention that the calibration of a small catchment can be challenging as catchment response to rainfall can be too quick as to be reproduced by the HBV model run with daily time steps. This challenge illustrates the need to calibrate the model with finer time steps (e.g., hourly).

A large degree of uncertainty is observed in runoff forecasting. The uncertainty in runoff forecasting is the result of the uncertainty in meteorological forecasts (precipitation and temperature) and in computed observed runoff. The error variability in runoff forecasts over time does not show any systematic pattern. In some cases, the runoff forecast made for a particular day seven days in advance shows a more reliable result than the forecast made for the same day one day prior. But this is not valid for all cases. Figure 10 shows the runoff forecast made on different dates and error variability over time.

These forecasted runoffs are used in the 


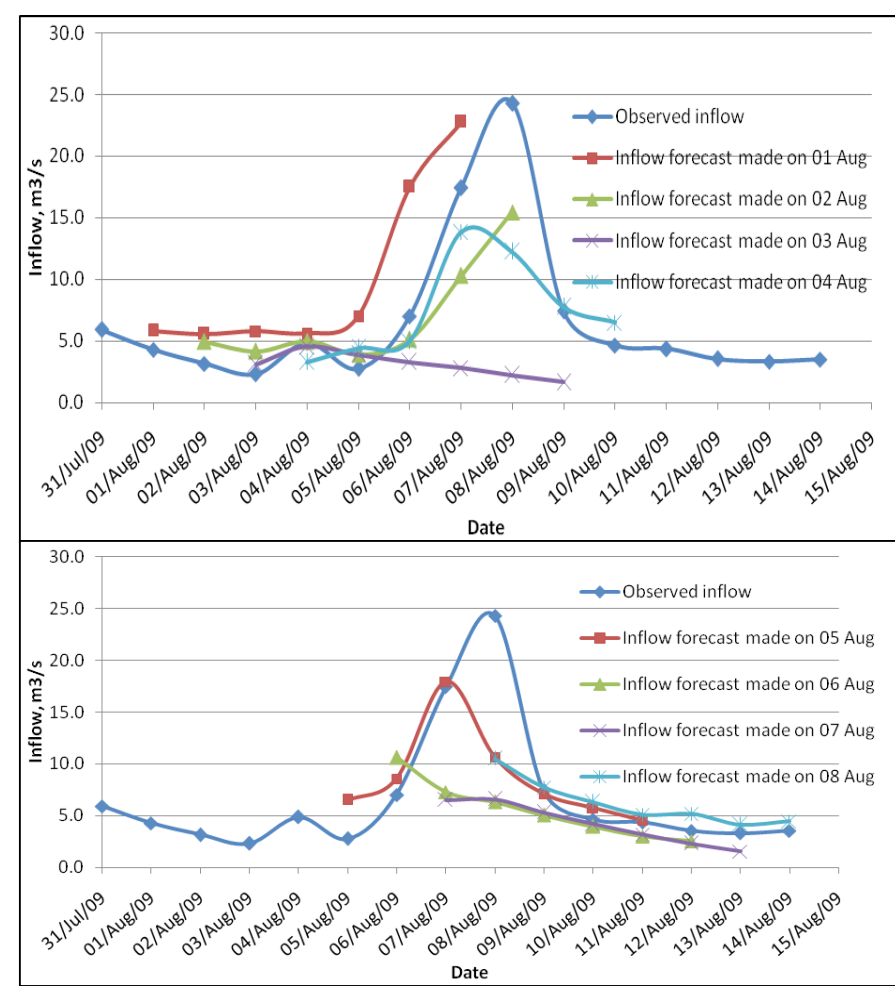

Figure 10: Uncertainty in short term runoff forecasting

existing reservoir model to estimate the capability of the plant to meet the energy demand and to predict reservoir level up to seven days in advance.

The reservoir operation model (Shrestha 2012) was run at each successive day from August 1, 2009 to August 8, 2009 based on the runoff forecasts made each day for seven days in advance. Table 2 shows the probable extent of load-shedding during the forecast period with respective model runs.

The model also predicts the reservoir level for the coming seven days with each model run from August 1 to August 8. The reservoir level in turn governs the reservoir operation strategy since it has to follow the predefined reservoir guide curve.

The uncertainty associated with runoff forecasts ultimately led to the uncertainty in reservoir operation. Figure 11 shows the reservoir level forecast and error variability over the time. Because of the uncertainty in the runoff forecasting, the reservoir operation model is unable to forecast the reservoir level precisely.

The reservoir operation model which is used here for demonstration purposes was developed by considering the existing situation of Kulekhani reservoir. In the future, if different prices for energy are set according to time of energy consumption and the real time energy demand on the Integrated Nepal Power System (INPS) grid, the runoff forecast will receive more attention in optimizing the reservoir operation to its best level.

\section{Flood warnings}

Runoff forecasting is a first crucial step to work with flood warning system. According to the Norwegian Water Resources and Energy Directorate (NVE; www. nve.no), flood warning limits are defined based on the re-occurrence frequency of the predicted runoff. For the flood warning, the same process of runoff forecasting is conducted and the forecasted runoff will be compared with the predetermined warning limits to decide whether warnings should be issued or not. Different types of warning messages will be issued based on the magnitude of the floods on the Kulekhani River as discussed below:

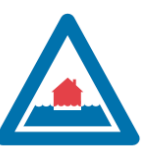

Notification offlooding: This notification is issued when the flow in the river is expected to exceed the flow with a re-occurrence interval of 5 years. The corresponding flow in Kulekhani River with 5 years return period is $345 \mathrm{~m} 3 / \mathrm{s}$ according to Gumbel's method.

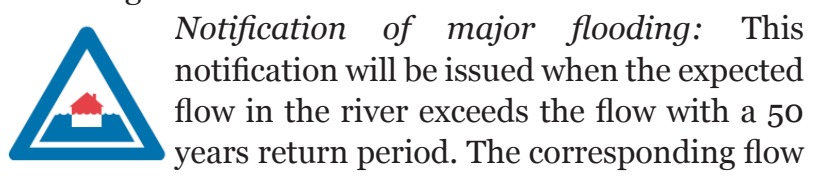
with 50 years return period is $685 \mathrm{~m}^{3} / \mathrm{s}$ according to Gumbel's method.

\section{Conclusion}

In conclusion, runoff forecasting can be a very useful tool in day to day energy optimization, effective reservoir operation, and establishing an effective flood warning system. This paper presents a working framework for reservoir operation considering the current energy pricing system in Nepal and operation of the plant to

\begin{tabular}{|c|c|c|c|c|c|c|c|c|c|c|c|c|c|c|}
\hline \multirow{2}{*}{$\begin{array}{l}\text { Forecast } \\
\text { made on }\end{array}$} & \multicolumn{14}{|c|}{ Loadshedding (MWh) forecast for the date } \\
\hline & 01.aug & 02.aug & 03.aug & 04.aug & 05.aug & o6.aug & 07.aug & 08.aug & 09.aug & 10.aug & 11.aug & 12.aug & 13.aug & 14.aug \\
\hline 01.aug.09 & & & & 23.9 & & & & & & & & & & \\
\hline 02.aug.09 & & & & 23.9 & & & & 8.8 & & & & & & \\
\hline 03.aug.09 & & & & 23.9 & & & & 8.8 & & & & & & \\
\hline 04.aug.09 & & & & 23.9 & & & & 8.8 & & & & & & \\
\hline 05.aug.09 & & & & & & & & 8.8 & & 6.5 & & & & \\
\hline 06.aug.09 & & & & & & & & 8.8 & & 6.5 & & & & \\
\hline 07.aug.09 & & & & & & & & 8.8 & & 6.5 & & & & \\
\hline 08.aug.09 & & & & & & & & 8.8 & & 6.5 & & & & 0.8 \\
\hline
\end{tabular}

Table 2: Load shedding forecast made on different date 


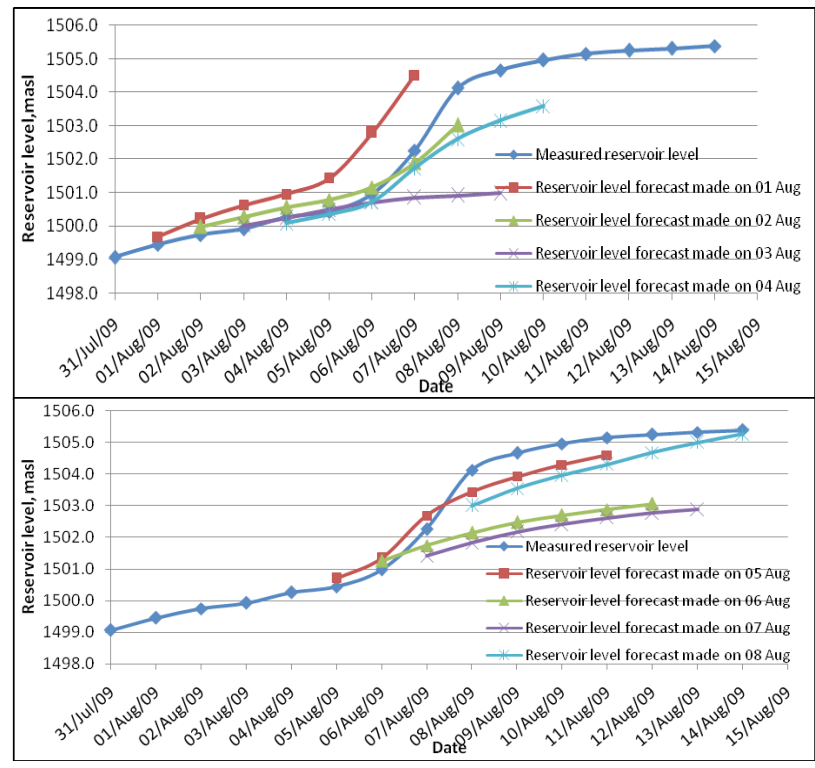

Figure 11: Uncertainty in reservoir level forecast and error variability

reduce loadshedding. In the future, if different prices for energy are set according to time of energy consumption and real time energy demand on the INPS grid and regional grid connection are included in the model, the runoff forecasting frame work could provide better utilization of water and better load coverage.

The uncertainty of observed runoff used in the model calibration and uncertainty of meteorological forecasts used in forecast simulation were the main sources of uncertainty in the runoff forecasting, which, in turn, would cause uncertainty in the reservoir operation and flood warning system. To improve the results in the subsequent application of runoff forecast, it is very important to work with good quality of runoff data and improved meteorological forecasts (i.e., finer spatial resolution) than the models used in this demonstration.

Anup Khanal, received a MSc degree in Hydropower Development from the Norwegian University of Science and Technology (NTNU), Norway using a scholarship from The Norwegian State Educational Loan Fund . He completed his master thesis in hydrology from Department of Hydraulic and Environmental Engineering. He also worked for student assistant position for hydrology at NTNU, Norway. Khanal has a working experience of two years on small hydropower projects in Nepal.

Corresponding address: zanup@hotmail.com

Netra Prasad Timalsina, holds master's degree in Hydropower Development from the Norwegian University of Science and Technology (NTNU), and is currently a PhD student in the same university and working on modeling river ice in a complex hydropower setting. He has nearly 11 years of work experience in hydropower planning, design and construction. His main field of interest is hydropower operation constraints in cold climates, hydrological and hydraulic modeling, programming, instrumentation, and primary field data collection.

Email:netra.timalsina@ntnu.no

Prof. Knut Alfredsen, is a professor in the Department of Hydraulic and Environmental Engineering at the Norwegian University of Science and Technology Since 2002,. Alfredsen holds a Ph.D. in Hydraulic Engineering from NTNU. His areas of research are hydrological modelling, cold climate hydrology, and environmental impacts of hydropower. He has published thirty papers in international peer-reviewed journals.

Email:knut.alfredsen@ntnu.no

\section{Foot Note}

1 http://rda.ucar.edu/datasets/ds335.0/\#description

2 Note again that 2009 was selected to demonstrate the forecast system due to lack of actual data for the spring of 2013 when the work was done.

\section{References}

Khanal, Anup, 2013. Master's Thesis. Inflow forecasting for Nepalese catchments, NTNU, Trondheim, Norway

Engen-Skaugen, T. 2007. Refinement of dynamically downscaled precipitation and temperature scenarios. Climatic Change, 84, 365-382.

Killingtveit, A. \& Saelthun, N. R. 1995. Hydrology, NTNU, Norwegian Institute of Technology, Division of Hydraulic Engineering.

Piani, C., Haerter, J. \& Coppola, E. 2010. Statistical bias correction for daily precipitation in regional climate models over Europe. Theoretical and Applied Climatology, 99, 187-192.

Ponce, V. M. 1989. Engineering hydrology: Principles and practices, Prentice Hall Englewood Cliffs.

Shrestha, H. S. 2012. Sedimentation and sediment handling in Himalayan reservoirs. Norwegian University of Science and Technology.

Team, R. C. 2011. R: a language and environment for statistical computing. Vienna, Austria: R Foundation for Statistical Computing; 2012. Open access available at: http://cran. r-project. org.

Xu, C. Y. \& Singh, V. 2001. Evaluation and generalization of temperature, based methods for calculating evaporation. Hydrological processes, 15, 305-319. 